\title{
Is a One Night Delay of Surgery Safe in Patients With Acute Appendicitis?
}

\author{
Jae Min Lee, Beom Seok Kwak, Young Jin Park \\ Department of Surgery, Dongguk University Ilsan Hospital, Ilsan, Korea
}

Purpose: With varied reports on the impact of time to appendectomy on clinical outcomes, the purpose of this study was to determine the effect of preoperative in-hospital delay on the outcome for patients with acute appendicitis.

Methods: A retrospective review of 1,076 patients who had undergone an appendectomy between January 2010 and December 2013 was conducted.

Results: The outcomes of surgery and the pathologic findings were analyzed according to elapsed time. The overall elapsed time from onset of symptoms to surgery was positively associated with advanced pathology, increased number of complications, and prolonged hospital stay. In-hospital elapsed time was not associated with any advanced pathology $(\mathrm{P}=$ $0.52)$, increased number of postoperative complications $(P=0.14)$, or prolonged hospital stay $(P=0.24)$. However, the complication rate was increased when the in-hospital elapsed time exceeded 18 hours.

Conclusion: Advanced pathology and postoperative complication rate were associated with overall elapsed time from symptom onset to surgery rather than in-hospital elapse time. Therefore, a short-term delay of an appendectomy should be acceptable.

Keywords: Appendicitis; Delayed appendectomy

\section{INTRODUCTION}

Acute appendicitis is one of the most common diseases requiring surgery. An instant emergent appendectomy at the time of diagnosis was the standard treatment for patients with acute appendicitis during the last century. Any delay in surgery was believed to increase postoperative complications or to cause a progression to complicated appendicitis, including perforation and abscess formation $[1,2]$. However, the concept of an emergency appendectomy has been challenged. Recent studies have suggested that delaying surgery does not increase morbidity after antibiotics therapy is initiated. Therefore, appendicitis can be managed with a

Received: September 7, 2017 - Accepted: October 11, 2017

Correspondence to: Young Jin Park

Department of Surgery, Dongguk University Ilsan Hospital, 27 Dongguk-ro, Ilsandong-gu, Goyang 10326, Korea

Tel: +82-31-961-7262, Fax: +82-31-910-7977

E-mail: parkyj@dumc.or.kr

ORCID code: https://orcid.org/0000-0002-3044-3289

(C) 2018 The Korean Society of Coloproctology

This is an open-access article distributed under the terms of the Creative Commons Attribution NonCommercial License (http://creativecommons.org/licenses/by-nc/4.0) which permits unrestricted noncommercial use, distribution, and reproduction in any medium, provided the original work is properly cited. semielective strategy $[3,4]$. On the other hand, some studies suggest that a delayed appendectomy is unsafe because it increases the risk of surgical site infection $[5,6]$.

The timing of surgery for appendicitis remains controversial. Further study is required to clarify this issue. Therefore, the objective of this study is to determine whether the complication rate is increased by a short-term delay of surgery for appendicitis. The data will be analyzed according to various time intervals, including whole elapsed time (from onset of symptoms to time of appendectomy), prehospital elapsed time (from onset of symptoms to hospital arrival), and in-hospital elapsed time (from hospital arrival to time of appendectomy).

\section{METHODS}

The medical records of patients who had undergone an appendectomy for acute appendicitis from January 2010 to December 2013 at Dongguk University Ilsan Hospital were retrospectively reviewed. This study was approved by the Institutional Review Board at Dongguk University Ilsan Hospital. The vast majority of these patients undergoing appendectomies at this hospital were admitted through the emergency room where they were first seen 
by an Emergency Department physician. Ultrasound or computed tomography scan images were obtained at the discretion of the Emergency Department physician. Surgical consultations were then done when investigations indicated any suspicions of appendicitis. Antibiotics (Meicelline, Youngjin Pham, Seoul, Korea) were administered for all patients immediately after the diagnosis of appendicitis. Patients with intraoperative finding of intraabdominal abscess or perforated appendicitis were given extended courses of antibiotics postoperatively. Appendectomies at this hospital are always initiated with a laparoscopic approach. Open conversion is done at any time when the surgeon judges that the laparoscopic procedure is unsafe or no longer possible.

Initially, all patients who had undergone an appendectomy during the above period were identified. To obtain comparability to published studies on appendicitis, we excluded cases with incidental, interval, or negative appendectomies and those with incomplete medical records. Data were then collected for the remaining 1,076 eligible patients. Data were gathered from electronic medical records and included the following parameters: demographic characteristics (age, sex), relevant clinical histories, white blood cell count, C-reactive protein (CRP) level, body temperature at admission, overall elapsed time, prehospital elapsed time, in-hospital delay, methods of surgery, final pathology, duration of hospital stay, any postoperative complication, and readmission within 30 days.

Age was analyzed as a categorical variable after the patients had been grouped according to age ( $\leq 15$ years, 16 to 65 years, and $>65$ years). All specimens were examined by a pathologist. The severity of the appendicitis was reported as suppurative, gangrenous, or perforated. A patient was defined as having perforated appendici- tis if a perforation was noted by the pathologist or if it was observed intraoperatively.

Demographics and clinical characteristics are expressed as means for continuous variables or proportions for categorical variables. The independent $t$-test was used for quantitative comparison of data with 2 variables while the one-way analysis of variance was used for data containing three variables. The chisquare test was used for qualitative comparisons between groups. A univariate linear regression analysis was performed to determine the association between elapsed time and duration of hospital stay. A receiver operating characteristic (ROC) curve analysis was used to determine the time at which the complication rate increased. IBM SPSS Statistics ver. 20.0 (IBM Co., Armonk, NY, USA) was used for all statistical analyses. A P-value of less than 0.05 was considered statistically significant.

\section{RESULTS}

A total of 1,076 patients were included in this study. Patient characteristics and their associations with pathologic grade are summarized in Table 1 . The mean \pm standard deviation age of these patients was $35.2 \pm 17.1$ years (range, $2-85$ years). Younger ( $\leq 15$ years) and older ( $>65$ years) age groups were associated with advanced pathology. Gangrenous appendicitis was observed in $21.4 \%$ of younger patients and $40.4 \%$ of older patients compared to $17.5 \%$ in the intermediate age group (16-65 years). Perforated appendicitis was also more frequent in the younger (14.8\%) and the older $(19.2 \%)$ age groups than in the intermediate $(5.8 \%)$ age group $(\mathrm{P}<0.01)$.

Fever, defined as a body temperature elevation over $37.8^{\circ} \mathrm{C}$ in

Table 1. Patients' characteristics based on pathologic findings of appendicitis

\begin{tabular}{|c|c|c|c|c|c|}
\hline Variable & Overall & Suppurative appendicitis & Gangrenous appendicitis & Perforated appendicitis & P-value \\
\hline №. (\%) & $1,076(100)$ & $760(70.6)$ & $220(20.4)$ & $96(8.9)$ & \\
\hline Age (yr) & $35.2 \pm 17.1$ & $34.7 \pm 17.7$ & $35.7 \pm 15.4$ & $36.5 \pm 18.2$ & \\
\hline$\leq 15$ & 196 (18.2) & $125(63.8)$ & $42(21.4)$ & $29(14.8)$ & $<0.01$ \\
\hline$>65$ & $104(9.7)$ & $42(40.4)$ & $42(40.4)$ & 20 (19.2) & $<0.01$ \\
\hline Reference $^{a}$ & $776(72.1)$ & $595(76.7)$ & $136(17.5)$ & $45(5.8)$ & \\
\hline Male sex & $612(56.9)$ & $424(69.3)$ & $131(21.4)$ & $57(9.3)$ & 0.92 \\
\hline Tarchycardia & $124(11.5)$ & $54(43.5)$ & 35 (28.2) & $25(20.1)$ & $<0.01$ \\
\hline Fever & $270(25.1)$ & $126(46.6)$ & $92(34.1)$ & $52(19.3)$ & $<0.01$ \\
\hline Leukocytosis & $783(72.8)$ & $519(66.3)$ & $179(22.9)$ & $85(10.9)$ & $<0.01$ \\
\hline CRP elevation & 712 (66.2) & $454(63.7)$ & $166(23.3)$ & $92(12.9)$ & $<0.01$ \\
\hline Open conversion & $20(1.9)$ & $7(35.0)$ & $8(40.0)$ & $5(25.0)$ & $<0.01$ \\
\hline Patient with complication & $85(7.9)$ & $41(48.2)$ & $25(29.4)$ & $19(22.4)$ & $<0.01$ \\
\hline Hospital stay (day) & $3.7 \pm 2.6$ & $3.4 \pm 2.5$ & $3.8 \pm 2.6$ & $5.3 \pm 2.8$ & $<0.01$ \\
\hline
\end{tabular}

Values are presented as number (\%) or mean \pm standard deviation. CRP, C-reactive protein.

${ }^{a} 16-65$ years. 
this study, was noted in 270 patients (19.2\%). Fever was correlated $(\mathrm{P}<0.01)$ with advanced pathology of appendicitis. Tachycardia, leukocytosis, and elevated value of CRP were also associated with appendicitis having a more severe pathology. Conversion to open surgery during laparoscopic appendectomy occurred in 20 cases $(1.9 \%)$. The open conversion rate increased with increasing pathologic grade: 7 conversions $(0.9 \%)$ in the suppurative appendicitis group, $8(3.6 \%)$ in the gangrenous appendicitis group, and $5(5.2 \%)$ in the perforated appendicitis group.

A total of 95 postoperative complications developed in 85 patients (7.9\%). Trocar site infection was the most frequent complication $(\mathrm{n}=36)$, followed by intra-abdominal abscess $(\mathrm{n}=19)$, ileus $(n=12)$, a lung problem $(n=6)$, readmission within 30 days $(n=7)$, and other minor problems $(n=15)$. Advanced pathology was significantly correlated with an increased postoperative complication rate and a prolonged hospital stay. The overall mean hospital stay was $3.7 \pm 2.6$ days. The duration of hospital stay was correlated $(\mathrm{P}<0.01)$ with advanced pathology.

The mean value of the overall elapsed time was $32.3 \pm 13.2$ hours. The overall elapsed time was categorized in 24-hour intervals for the convenience of analysis. A significant $(\mathrm{P}<0.01)$ association between the overall elapse time and a more advanced pathology was found. To obtain comparability with published data, we grouped the in-hospital elapsed time in 6-hour intervals; we found that the in-hospital elapsed time was not significantly $(\mathrm{P}=$ 0.40) associated with pathology (Table 2).

Both the overall elapsed time and the prehospital elapsed time were strongly associated with the development of postoperative complications. The in-hospital elapsed time was associated with postoperative complications with marginal statistical significance $(\mathrm{P}=0.06)$. One of the purposes of this study was to reveal how long an appendectomy could be delayed without significantly increasing the complication rate. The analysis showed that the complication rate was increased when the in-hospital elapsed time ex-

Table 2. Pathologic findings, number (\%), according to overall, prehospital, and in-hospital elapsed time

\begin{tabular}{|c|c|c|c|c|c|}
\hline Time (hr) & $\begin{array}{c}\text { Total } \\
\text { number }\end{array}$ & $\begin{array}{l}\text { Suppurative } \\
(\mathrm{n}=760)\end{array}$ & $\begin{array}{l}\text { Gangrenous } \\
(\mathrm{n}=220)\end{array}$ & $\begin{array}{c}\text { Perforated } \\
(\mathrm{n}=96)\end{array}$ & P-value \\
\hline \multicolumn{6}{|c|}{ Overall elapsed time } \\
\hline$<24$ & 266 & $213(80.1)$ & 45 (16.9) & $8(3.0)$ & - \\
\hline $24-48$ & 490 & $381(77.7)$ & $84(17.1)$ & $25(5.1)$ & $<0.01$ \\
\hline $48-72$ & 130 & $79(60.8)$ & $31(23.8)$ & $20(15.4)$ & - \\
\hline$>72$ & 190 & $87(45.8)$ & $60(31.6)$ & $43(22.6)$ & - \\
\hline \multicolumn{6}{|c|}{ In-hospital delay time } \\
\hline$<6$ & 367 & $270(73.6)$ & 70 (19.1) & $27(7.4)$ & - \\
\hline $6-12$ & 395 & $280(70.9)$ & $83(21.0)$ & $32(8.1)$ & 0.40 \\
\hline $12-18$ & 221 & $150(67.9)$ & $46(20.8)$ & $25(11.3)$ & - \\
\hline$>18$ & 93 & $60(64.5)$ & $21(22.6)$ & 12 (12.9) & - \\
\hline
\end{tabular}

Values are presented as number (\%). ceeded 18 hours (Table 3 ). To more clearly define the time for which the complication rate increased sharply, we performed a ROC curve analysis. The optimal cutoff time was 22.5 hours, with $33.5 \%$ sensitivity, and $93.1 \%$ specificity (Fig. 1). This suggests that a relatively short-term delay, which does not exceed 18 hours, of

Table 3. Complication rates according to overall, pre-hospital, and in-hospital elapsed time

\begin{tabular}{lccc}
\hline Time (hr) & No. of patients & $\begin{array}{c}\text { No. of with } \\
\text { complications (\%) }\end{array}$ & P-value \\
\hline $\begin{array}{l}\text { Overall elapsed time } \\
<24\end{array}$ & 266 & $11(4.1)$ & - \\
$24-48$ & 490 & $34(6.9)$ & $<0.01$ \\
$48-72$ & 130 & $14(10.8)$ & - \\
$>72$ & 190 & $26(13.7)$ & - \\
Pre-hospital elapsed time & & & \\
$<24$ & 422 & $23(5.5)$ & - \\
$24-48$ & 412 & $31(7.5)$ & $<0.01$ \\
$48-72$ & 120 & $13(10.8)$ & - \\
$>72$ & 122 & $18(14.7)$ & - \\
In-hospital delay time* & & & - \\
$0-6$ & 367 & $25(6.8)$ & - \\
$6-12$ & 395 & $29(7.3)$ & $0.06^{*}$ \\
$12-18$ & 221 & $17(7.7)$ & - \\
$>18$ & 93 & $14(15.1)$ & - \\
\hline
\end{tabular}

${ }^{*} \mathrm{P}=0.91$ when the variable of $>18$ hours was excluded.

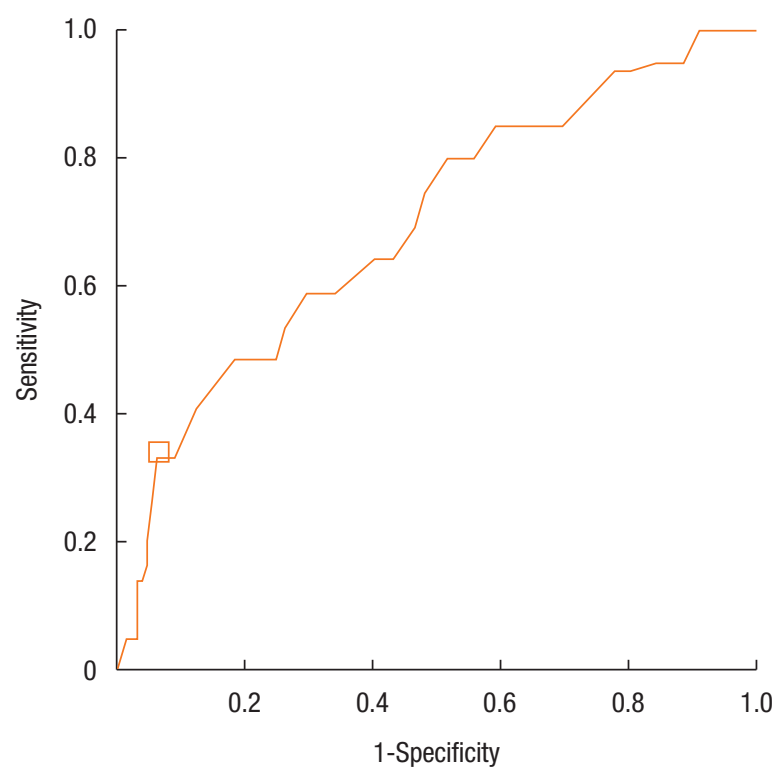

Fig. 1. Receiver operating characteristic curve for the sensitivity vs. 1-specificity. The optimal cutoff point is marked as a white square box on the graph. 
an appendectomy does not increase the complication rate. The length of hospital stay was greater in proportion to the increased overall elapsed time $(\mathrm{P}<0.01)$ and to the increased pre-hospital elapsed time $(\mathrm{P}<0.01)$. However, it was not associated with the in-hospital elapsed time $(\mathrm{P}=0.24)$.

\section{DISCUSSION}

Although the exact mechanism of acute appendicitis remains unclear, luminal obstruction of the appendix is believed to be the major cause [7]. Obstruction of the appendiceal lumen contributes to bacterial overgrowth and continued secretion of mucus, leading to intraluminal distension and increased wall pressure, which can reduce blood flow and result in necrosis and perforations. An emergency appendectomy has been regarded as mandatory until recently because appendicitis is an irreversible progressive disease. Surgical delay might increase the perforation rate and morbidity. The necessity for a prompt appendectomy is still widely supported by many authors. Ditillo et al. [5] found that the risk of developing advanced pathology and complications increased with time in adult patients with acute appendicitis, suggesting that a delay in performing the appendectomy was unsafe. Busch et al. [8] reported that an in-hospital delay of more than 12 hours was an independent risk factor for perforation. In addition, the consensus from the 2015 meeting of the European Association of Endoscopic Surgery recommended an early appendectomy as an official opinion regardless of contrary views [9].

Recently, many authors have raised doubts about the irreversibility in the progress of appendicitis. They argue that not all acute appendicitis cases progress to perforation and that appendicitis heals spontaneously in many patients [10]. Based on this idea, nonoperative management with antibiotics has been suggested and practiced for patients with uncomplicated appendicitis [11]. In addition, the necessity of emergent surgery has been contradicted by many pieces of evidence. Kim et al. [12] found that surgical morbidity was not affected by surgical delay, but was determined by overall symptom duration. In a large population-based study that used the American College of Surgeons National Surgical Quality Improvement Program database, Ingraham et al. [13] showed that a delayed appendectomy was not associated with increased morbidity. A cohort study by the United Kingdom National Surgical Research Collaborative showed that a short delay in performing an appendectomy did not increase the complication rate [14].

The results of the present study also support the view that semielective surgery for patients with acute appendicitis does not increase the postoperative complication rate or prolong the hospital stay. In more detail, increased overall and prehospital elapsed time increased both the proportion of cases with advanced pathology and the rate of postoperative complications. However, the in-hospital elapsed time did not affect the outcome in our study. This might be due to the assumptions that most perforations in appendicitis occur before patients are admitted to hospital and that a substantial portion of appendicitis cases might have resolved spontaneously rather than progressed to perforation. According to Andersson [10], uncomplicated acute appendicitis can be self-limiting, with frequent spontaneous resolution. Therefore, acute appendicitis does not very often progress to perforation while the patient is in the Emergency Department. In our patients, prompt administration of antibiotics after the appendicitis diagnosis might have impeded the progression of appendicitis. Much recent research has shown that antibiotics alone can be used to treat patients with uncomplicated acute appendicitis [11, 15 ] and that such treatment can halt the inflammatory process of perforated appendicitis [16].

The association between perforated appendicitis and worse clinical outcome has been well established $[1,2]$. Multiple studies have reported that the presence of complex appendicitis is the predominant determinant of postoperative complications [1, 4]. Boomer et al. [17] reported that complex appendicitis was the only significant factor in predicting an increased complication rate. Abbas et al. [18] also demonstrated that the disease severity of appendicitis was the strongest predictor of surgical outcome.

The results of our study showed that advanced pathology (including gangrenous and perforated appendicitis) was more frequent in the younger and the older age groups than in the intermediate age group, regardless of time dely. Whether the natural course of appendicitis progression differs according to the age of patient is unclear. Nevertheless, an earlier operation would be desirable in these age groups because delayed surgery on a patient with perforated appendicitis can significantly increase the postoperative complication rate.

Although surgeons try to avoid any delay of surgery for appendicitis, a prompt operation is not always feasible. The preoperative evaluation or consultation can be time consuming for patients with comorbidities. A limitation in the available surgical facilities may also cause a delay of surgery. In addition, a large portion of patients with acute appendicitis visit the hospital in the evening or around midnight, at which times operating team members, such as an anesthesiologist, nurses, and assistants, are not always available. The results of this study might lessen the surgeon's stress in such situations as the risk of increasing perforation and subsequent morbidity in patients with appendicitis by delaying surgery might not be as significant as previously thought. Flexible adjustment of the surgery schedule could increase effective utilization of medical resources and lessen surgeon's fatigue.

Our results showed that the complication rate was increased when the in-hospital elapsed time exceeded 18 hours, which was consistent with many other reports $[19,20]$. Based on previous reports and our experience, a short time delay of surgery for patients with appendicitis should be safe. For example, the surgery could be delayed to the next day for nighttime visitors with acute appendicitis. However, a delay of longer than 1 day should be avoided because such a delay would increase the complication 
rate.

This study has several limitations. First, this study was a singlehospital-based retrospective analysis. Data collection based on electrical medical chart was often impaired by poor documentation regarding patient's presentation. In addition, patient's history or review of symptoms was not standardized. Therefore, these data might be inaccurate. In addition, cases with incomplete medical record were excluded from this study. That the data were not from consecutive cases might have led to selection bias.

In summary, our results demonstrate that the postoperative complication rate in patients with appendicitis was associated with overall elapsed time from symptom onset to surgery rather than with in-hospital elapsed time. Furthermore, an in-hospital delay of the appendectomy by 18 hours or less did not adversely affect the surgical outcome. Therefore, a short-term delay of an appendectomy can be acceptable under certain conditions.

\section{CONFLICT OF INTEREST}

No potential conflict of interest relevant to this article was reported.

\section{REFERENCES}

1. Temple CL, Huchcroft SA, Temple WJ. The natural history of appendicitis in adults. A prospective study. Ann Surg 1995;221:27881.

2. Berry J Jr, Malt RA. Appendicitis near its centenary. Ann Surg 1984;200:567-75.

3. Stahlfeld K, Hower J, Homitsky S, Madden J. Is acute appendicitis a surgical emergency? Am Surg 2007;73:626-9.

4. Kearney D, Cahill RA, O'Brien E, Kirwan WO, Redmond HP. Influence of delays on perforation risk in adults with acute appendicitis. Dis Colon Rectum 2008;51:1823-7.

5. Ditillo MF, Dziura JD, Rabinovici R. Is it safe to delay appendectomy in adults with acute appendicitis? Ann Surg 2006;244:65660.

6. Teixeira PG, Sivrikoz E, Inaba K, Talving P, Lam L, Demetriades D. Appendectomy timing: waiting until the next morning increases the risk of surgical site infections. Ann Surg 2012;256:538-43.

7. Prystowsky JB, Pugh CM, Nagle AP. Current problems in surgery. Appendicitis. Curr Probl Surg 2005;42:688-742.

8. Busch M, Gutzwiller FS, Aellig S, Kuettel R, Metzger U, Zingg U.
In-hospital delay increases the risk of perforation in adults with appendicitis. World J Surg 2011;35:1626-33.

9. Gorter RR, Eker HH, Gorter-Stam MA, Abis GS, Acharya A, Ankersmit M, et al. Diagnosis and management of acute appendicitis. EAES consensus development conference 2015. Surg Endosc 2016;30:4668-90.

10. Andersson RE. The natural history and traditional management of appendicitis revisited: spontaneous resolution and predominance of prehospital perforations imply that a correct diagnosis is more important than an early diagnosis. World J Surg 2007;31:8692.

11. Salminen P, Paajanen H, Rautio T, Nordström P, Aarnio M, Rantanen T, et al. Antibiotic therapy vs appendectomy for treatment of uncomplicated acute appendicitis: The APPAC Randomized Clinical Trial. JAMA 2015;313:2340-8.

12. Kim M, Kim SJ, Cho HJ. Effect of surgical timing and outcomes for appendicitis severity. Ann Surg Treat Res 2016;91:85-9.

13. Ingraham AM, Cohen ME, Bilimoria KY, Ko CY, Hall BL, Russell TR, et al. Effect of delay to operation on outcomes in adults with acute appendicitis. Arch Surg 2010;145:886-92.

14. United Kingdom National Surgical Research Collaborative, Bhangu A. Safety of short, in-hospital delays before surgery for acute appendicitis: multicentre cohort study, systematic review, and meta-analysis. Ann Surg 2014;259:894-903.

15. Eriksson S, Granström L. Randomized controlled trial of appendicectomy versus antibiotic therapy for acute appendicitis. Br J Surg 1995;82:166-9.

16. Andersson RE, Petzold MG. Nonsurgical treatment of appendiceal abscess or phlegmon: a systematic review and meta-analysis. Ann Surg 2007;246:741-8.

17. Boomer LA, Cooper JN, Deans KJ, Minneci PC, Leonhart K, Diefenbach KA, et al. Does delay in appendectomy affect surgical site infection in children with appendicitis? J Pediatr Surg 2014; 49:1026-9.

18. Abbas PI, Peterson M, Stephens LJ, Rodriguez JR, Lee TC, Brandt $\mathrm{ML}$, et al. Evaluating the effect of time process measures on appendectomy clinical outcomes. J Pediatr Surg 2016;51:810-4.

19. Al-Qurayshi Z, Kadi A, Srivastav S, Kandil E. Risk and outcomes of 24-h delayed and weekend appendectomies. J Surg Res 2016; 203:246-52.e1.

20. Jeon BG, Kim HJ, Jung KH, Lim HI, Kim SW, Park JS, et al. Appendectomy: should it be performed so quickly? Am Surg 2016; 82:65-74. 